\title{
Empirical findings on Critical Infrastructure Dependencies in Europe
}

Eric Luiijf, Albert Nieuwenhuijs, Marieke Klaver, Michel van Eeten and Edite Cruz

\begin{abstract}
One type of threat consistently identified as a key challenge for Critical Infrastructure Protection (CIP) is that of cascading effects caused by dependencies and interdependencies across different critical infrastructures (CI) and their services. This paper draws on a hitherto untapped data source on infrastructure dependencies: a daily maintained database containing over 2375 serious incidents in different $\mathrm{CI}$ all over the world as reported by news media. In this paper we analyse this data to discover patterns in CI failures in Europe like cascades, dependencies, and interdependencies. Some analysis results indicate that less sectors than many dependency models suggest drive cascading outages and that cascading effects due to interdependencies are hardly reported.
\end{abstract}

\section{Introduction}

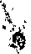

Most nations and the European Union [1] have identified that critical infrastructures (CI) dependencies are causes of major concern. A failure within a single $\mathrm{CI}$ may already be damaging enough to society. However, when such a failure cascades across CI boundaries, then the potential for multi-infrastructural collapse and high catastrophic damages may be high. Various modelling and simulation efforts also stress the possibility of dependencies and cascading failure. But just how to rate this type of risk in comparison to other risk factors for $\mathrm{CI}$, remains unclear. While probabilities are unknown, the magnitude of the consequences multi-sector collapse is so large that many argue that this factor alone pushes this risk to the top of national priority lists. Auerswald [2] calls Cl dependencies the unmanaged challenge, which has proven to be less tractable than managing the vulnerabilities within a single CI: More pervasive and difficult to manage are the (inter)dependencies that exist among firms in different infrastructures. Most national CI protection (CIP) policies identify dependencies as a priority area. Adequately addressing this unmanaged challenge will draw substantial resources away from other CIP areas. The question is whether the risk associated with $\mathrm{CI}$ dependencies, and if so, for which set of $\mathrm{CI}$, needs to be prioritised. A confrontation with em-

Eric Luiijf, Albert Nieuwenhuijs and Marieke Klaver

TNO Defence, Security and Safety, Oude Waalsdorperweg 63, 2597AK The Hague, The Netherlands, e-mail: \\{eric.luiijf, albert.nieuwenhuis, marieke.klaver $\backslash\} @$ tno.nl, www. tno.nI

Michel van Eeten and Edite Cruz

Faculty of Technology, Policy and Management Technical University of Delft, PO Box 5015, 2600

GA Delft, The Netherlands e-mail: m.j.g.vaneeten@tudelft.nl 
pirical data, even if scarce or incomplete, may help in decision-taking and prioritising. So far, such efforts as far as the authors know are by and large missing.

This paper draws on a hitherto untapped data source on $\mathrm{CI}$ dependencies: a database containing recordings of $2517 \mathrm{CI}$ failures (as of July 30, 2008) and their cascading outages. The authors analyse this data to discover patterns in $\mathrm{Cl}$ failures across different $\mathrm{Cl}$ in the world, in Europe, and in the Netherlands.

The outline of this paper is as follows: in Section 2 we review the state of the art of current research on $\mathrm{CI}$ dependencies. Section 3 shortly discusses the scope, method and limitations of our analysis. In Section 4, we present our data analysis findings for Europe. Section 5 contains the conclusions and the implications of our analysis.

\section{Dependencies - state of the art}

Most $\mathrm{CI}$ dependency literature use a theoretical modelling approach to dependencies, e.g., Rinaldi et al, [4] and Svendsen and Wolthuysen [6]. Most post mortem analysis reports about $\mathrm{Cl}$ disruption incidents describe the incident from a single $\mathrm{Cl}$ view, e.g., [9]. Cascading effects and dependency consequences are often hidden in government reports about their emergency response efforts to disasters, e.g., Von Kirchbach [8]. Other research focuses on the modelling and simulation of CI and cross-links between different $\mathrm{Cl}$ sectors [3]. Generally spoken, these models are not based on real life data or on a full dependency analysis of past incidents. The empirical work in this paper discusses observations made on $\mathrm{CI}$ dependencies based on news and other reports about serious $\mathrm{CI}$ events. There exist, however, databases which focus on collecting empirical data of infrastructure incidents. Without exception, however, these databases focus on a specific environment, a single $\mathrm{Cl}$ sector, or a specific type of risk. Examples of foci of such databases are for instance terrorism-caused energy infrastructure disruptions, process industry safety, electric power disturbances (e.g., national or European grid disturbance reports), radiological incidents, and aircraft incidents (e.g., $[5,7,10])$. No databases have been found which focus on serious disturbances of all $\mathrm{CI}$ and the cascading effects using an all-hazards approach.

\section{Method}

At the core of our analysis is a database with public reports of $\mathrm{CI}$ disruptions, collected from open sources like newspapers and internet news outlets. If possible, the data is augmented by official incident reports. An event in one of the CI sectors will be added to the database if there is a serious impact: only events are recorded which affected at least $10.000 \mathrm{CI}$ customers (households and businesses), or which had for other reasons a (potential) noticeable effect to society. Daily occurring local and scheduled operational disturbances are therefore excluded. For each event we record, e.g., affected $\mathrm{Cl}$ sector and service, initiating event, the concerned organisation(s), start and end times/dates, country, affected geographic area and its size, description of the cause, threat category and subcategory, consequences/damages and impact, the duration of recovery, and one or more references. While data has been collected on a variety of countries in the world, for the purposes of this paper we focus on a subset: $1749 \mathrm{CI}$ failure incidents in 29 European nations (95\% of them occurred after 2000). Based on this subset, we empirically study CI (inter)dependencies. $\mathrm{A} \mathrm{Cl}$ dependency is the relationship between two $\mathrm{Cl}$ products or services in which one product or service is required for the generation of the other product or service; a $\mathrm{CI}$ interdependency is a mutual CI dependency.

We understand that the data set and approach has limitations. We explored the validity of the findings by triangulating the Dutch national data with outage data from a Dutch $\mathrm{CI}$ operator. We 
also found self-similarities in the Dutch, EU and US subsets of the event database. However, we realise that the data is biased by the limited set of European languages (Dutch, English, French, German, Portuguese, and Spanish) which we use to identify and extract media reports. Another bias may be the reporting practices of news media as not every serious $\mathrm{CI}$ incident is reported by news media. Among other factors, the news reports likely reflect what the news outlets assume is of interest to their audience. It is not clear if and how our findings are affected by these limitations. We are not aware of any research that has studied biases in how the media report on CI failures. That said, we believe that in light of the overall paucity of empirical research on this topic our analysis contributes much needed data to the policy debates on CIP and the risk of CI cascading failure.

In our analysis, we will classify events in cascade initiating events, cascade resulting events and independent events. A cascade initiating event is an event that causes an event in another $\mathrm{CI}$ or CI service; a cascade resulting event is an event that results from an event in another $\mathrm{CI}$ or $\mathrm{CI}$ service, and an independent event is an event that is neither a cascade initiating event, nor a cascade resulting event. These categories are not mutually exclusive. Because an event can be both caused by an event outside a CI sector and propagate as another event outside the $\mathrm{CI}$ sector, some events are both a cascade initiating and a resulting event. This may cause the sum of initiating, resulting and independent events to exceed the total number of events (e.g., Total column in Table 1).

It should be noted that the analysis below is performed at the level of CI services. This means that we only consider a cascading resulting event to be a dependency -and include it into the resultsif the event takes place in another CI service than the one of the cascade initiating event. For readability, most results below are aggregated to the $\mathrm{CI}$ sector level. Consequently, dependencies between underlying services within a $\mathrm{CI}$ sector appear as within a single $\mathrm{CI}$ sector.

\section{Dependencies across Critical Infrastructures in Europe}

\subsection{Number of cascades}

We have first analysed the data by distinguishing cascading events from non-cascading events (Table 1). Interestingly, $29 \%$ of the reported incidents in Europe result from incidents in other services (501 of the 1749 events). Anecdotal evidence about dependencies and cascading sometimes conveys the sense of reporting on rather unlikely scenarios, suggesting that cascades are events of low probability and high consequence. Our data, however, shows that they are significant more frequent.

\subsection{Directionality of cascades}

Next, we established in which CI sector does an event originate and which CI sectors are affected (Table 2). The events that are not cascade related are labelled no sector. They comprise disruptions due to a large range of external events (e.g., weather, deliberate human actions, and economical factors) and internal failures (e.g., human error, technical failure). Table 2 shows that the energy and telecommunication sectors are the main cascading initiating sectors. Energy is the only sector which initiates more cascades than it ends up receiving. When disregarding not cascade initiated events, the empirical data confirms that the dependency matrix is sparsely populated and that cascades are highly asymmetrical. The energy and telecommunication sectors cause outages in other sectors ( $60 \%$ and $24 \%$ respectively), but not many other CI sectors cause outages in the energy, telecommunication and internet sectors (Table 2). The affected energy, telecommunication and in- 
Table 1: Categorisation of number of CI disruption events (number of events).

\begin{tabular}{l|rrr|r|r}
\hline CI Sector & $\begin{array}{l}\text { Cascade Cascade Independent } \\
\text { initiating resulting }\end{array}$ & Total & $\begin{array}{r}\text { Sample } \\
\text { size }\end{array}$ \\
\hline Education & 0 & 3 & 1 & 4 & 4 \\
Energy & 146 & 76 & 388 & 609 & 590 \\
Financial Services & 1 & 26 & 33 & 60 & 60 \\
Food & 0 & 4 & 3 & 8 & 8 \\
Government & 2 & 40 & 26 & 68 & 67 \\
Health & 1 & 16 & 22 & 39 & 39 \\
Industry & 5 & 15 & 7 & 27 & 27 \\
Internet & 15 & 51 & 95 & 161 & 160 \\
Postal Services & 1 & 0 & 0 & 1 & 1 \\
Telecom & 69 & 125 & 114 & 308 & 295 \\
Transport & 19 & 128 & 276 & 423 & 422 \\
Water & 9 & 18 & 51 & 78 & 76 \\
\hline Total & 268 & 501 & 1017 & 1786 & 1749 \\
\hline
\end{tabular}

ternet sector event percentages of $15 \%, 25 \%$ and $10 \%$, respectively, are for a large part generated by services within these three sectors. In short, the dependencies are very focused and directional. In fact, one may want to stop talking about inter-dependencies, as this suggests a reciprocal relationship that the data simply does not warrant as occurring frequently. Actually, the database contains only two weak European interdependency events.

Table 2: Events categorised by initiating sector and affected sector (\# of events).

\begin{tabular}{|c|c|c|c|c|c|c|c|c|c|}
\hline \multirow[b]{2}{*}{ CI Sector } & \multicolumn{9}{|c|}{ Initiating sector } \\
\hline & $\begin{array}{l}\vdots \\
0 \\
0 \\
0 \\
0 \\
2\end{array}$ & 焉 & 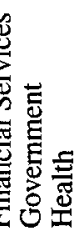 & 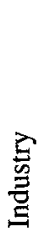 & $\begin{array}{l}\text { 氖哥 } \\
\text { 总 }\end{array}$ & 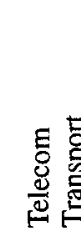 & & 芠 & 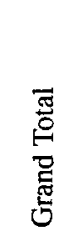 \\
\hline Educatic & 1 & 1 & & & & & & 2 & 4 \\
\hline Energy & 515 & 65 & & 4 & & 21 & 13 & 3 & 589 \\
\hline Financial Services & 34 & 53 & & & 3 & 15 & & & 60 \\
\hline Food & 4 & 3 & & & & & 1 & & 8 \\
\hline Government & 27 & 17 & 11 & 1 & 4 & 14 & 1 & 1 & 67 \\
\hline Health & 23 & 11 & 2 & & & 2 & & 1 & 39 \\
\hline Industry & 12 & 12 & & 1 & & & 1 & 1 & 27 \\
\hline Internet & 109 & 14 & & & 10 & 27 & & & 160 \\
\hline Postal Serv & 1 & & & & & & & & 1 \\
\hline Telecom & 170 & 62 & & & 1 & 575 & 5 & & 295 \\
\hline Transport & 294 & 98 & 1 & 3 & 1 & 515 & 5 & 5 & 422 \\
\hline Water & 58 & 14 & & 2 & & & & 2 & 76 \\
\hline Total & 1248 & 302 & 323 & 11 & 18 & 1 & 15 & \begin{tabular}{l|l}
5 & 1 \\
\end{tabular} & 1749 \\
\hline
\end{tabular}


This raises an important issue: does this mean that, while dependencies and interdependencies are everywhere, at least theoretically, they are rarely strong enough to trigger a secondary outage which is reported by the news media? Do they only occur after a longer period of disruption than is often the case? Or are these cascading outage events so hidden in the chaos caused by the primary $\mathrm{CI}$ outage and its effects that the press does not report on them?

The dependency of many sectors on energy and telecommunications has been reported widely. The Table 3 data suggests that the CI dependency on energy is substantially higher (taken mitigation measures into account) as $60 \%$ of all cascades originate within the energy sector, $28 \%$ in the telecommunication and internet sectors, and $5 \%$ in the transport sector, $3 \%$ in the water sector, and $4 \%$ in the remaining $\mathrm{CI}$.

\subsection{Energy and Telecom sector services}

A good practice is to strictly separate the office automation and the SCADA environments and to have a strictly controlled data exchange between these environments, if required at all.

The Energy sector column in Table 2 shows that the energy sector is an important cascade initiating sector for almost all sectors. The second largest is the telecommunication sector. When we consider the energy sector services in Europe, it can be concluded that the initiating events for a large majority originate within the electrical power service (see Table 3). It can be deducted that serious disruptions of electric power has affected almost all CI sectors and services. When considering also cascading between $\mathrm{CI}$ services within a $\mathrm{CI}$ sector, 61 dependencies exist between the electrical power sector services generation, transmission and distribution. Only in four cases the oil and gas subsectors were affected. The telecommunication services fall apart in the backbone networks and their services, cable/CATV services, the fixed telecommunication system (e.g., POTS, DSL-services, leased line services, alarm line services), mobile telephony, and SMS. As the telecom sector column in Table 2 indicates, this sector is an important initiator for events in the financial services, the government services, and the internet and telecom sectors themselves. Due to the sector structure, disruptions of telecom backbones more seriously affect internet services than other telecom services. In the same way, the loss of cable/CATV services affects the access to internet and voice services over cable for citizens.

Detailed analysis of the database shows that the financial sector only seems to be affected by disruptions in the fixed telecommunications infrastructure in the functioning of automated teller machines and electronic payment systems. Also the emergency response and 1-1-2 services are affected by fixed infrastructure failures. As most mobile telecommunication transmission between base stations (antennas) and the base station controllers (BSC) in Europe use the standard fixed telecommunication infrastructure, it is not surprising that fixed telecommunication disruptions in Europe most often impact GSM/UMTS services.

\subsection{Escalation of cascades}

The domino theory suggests that serious $\mathrm{CI}$ failures result in a sequence of disruptions in other CI. Table 5, however, shows that on average a cascade initiating event in the energy sector triggers 2,06 distuptions in other CI services. A cascade initiating event in the telecommunication sector on average triggers 1,86 disruptions in other $\mathrm{CI}$ services. Considering all events (including all independent events), Table 5 also shows that one out of two events in the energy sector triggers a disruption in another $\mathrm{CI}$ and just above two out of five events in the telecommunication sector triggers another disruption. Analysis also shows that 421 events or $24 \%$ of the 1749 events, are a first 
Table 3: Cascade initiated events categorised by affected sector (percentage of events contributed to an affected sector).

\begin{tabular}{|c|c|c|c|c|c|c|c|c|c|c|c|}
\hline \multirow[b]{2}{*}{ CI Sector } & \multicolumn{11}{|c|}{ Initiating sector } \\
\hline & 产 & 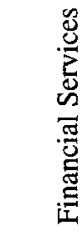 & 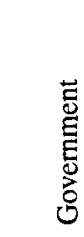 & 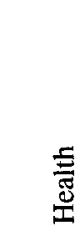 & 咆 & 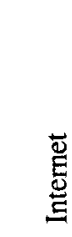 & 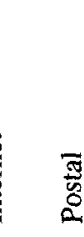 & $\frac{\Xi}{0}$ & 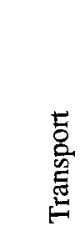 & 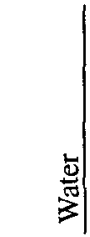 & 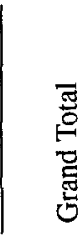 \\
\hline Education & $0 \%$ & & & & & & & & & $13 \%$ & $1 \%$ \\
\hline Energy & $22 \%$ & & & & $36 \%$ & & & $2 \%$ & $4 \%$ & $20 \%$ & $15 \%$ \\
\hline Financial Services & & $100 \%$ & & & & $17 \%$ & & $12 \%$ & & & $5 \%$ \\
\hline Food & $1 \%$ & & & & & & & & $4 \%$ & & $1 \%$ \\
\hline Government & $6 \%$ & & $50 \%$ & $33 \%$ & $9 \%$ & $22 \%$ & & $11 \%$ & $4 \%$ & $7 \%$ & $8 \%$ \\
\hline Health & $4 \%$ & & & $67 \%$ & & & & $2 \%$ & & $7 \%$ & $3 \%$ \\
\hline Industry & $4 \%$ & & & & $9 \%$ & & & & & $7 \%$ & $3 \%$ \\
\hline Internet & $5 \%$ & & & & & $56 \%$ & & $22 \%$ & & & $10 \%$ \\
\hline Po-lal Services & & & & & & & & & & & $0 \%$ \\
\hline Telecom & $21 \%$ & & & & & $6 \%$ & & $47 \%$ & $21 \%$ & & $25 \%$ \\
\hline Transport & $32 \%$ & & $50 \%$ & & $27 \%$ & & $100 \%$ & $4 \%$ & $83 \%$ & $33 \%$ & $26 \%$ \\
\hline Water & $5 \%$ & & & & $18 \%$ & & 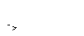 & & & $13 \%$ & $4 \%$ \\
\hline Total & $100 \%$ & $100 \%$ & $100 \%$ & $100 \%$ & $100 \%$ & $100 \%$ & $100 \%$ & $100 \%$ & $100 \%$ & $100 \%$ & $100 \%$ \\
\hline \# of events & 203 & 3 & 2 & 3 & 11 & 18 & 1 & 122 & 24 & 15 & 501 \\
\hline
\end{tabular}

level of cascade event, 76 events ( $4 \%$ ) are the result of a second cascade, and 4 events are caused by a third cascade. No deeper cascades have been found, neither in Europe, nor internationally.

\section{Conclusions}

Our findings raise several important issues. First, while the current literature gives very little clues as to the probability of cascading failures, our empirical data suggests that such cascades are in fact fairly frequent. This forms a sharp contrast with the typical examples of events of low probability and high consequence that are often presented as evidence of the urgency of dealing with CI dependencies. Second, they question the validity of the Domino Theory of CI. While there are an almost unlimited number of dependencies and interdependencies among $\mathrm{Cl}$ possible, i.e., there are many pathways along which failures may propagate $\mathrm{CI}$ sector boundaries, we found that this potential is not expressed in the empirical data on actual events. The cascades that were reported were highly asymmetrical and focused. The overwhelming majority of them originated in the energy and telecom sectors. This is not unexpected, but what is new is the fact that so few cascades took place in other CI sectors. Third, interdependencies far less occur than analysts have consistently modelled. We found only two cases on a total of some $770 \mathrm{CI}$ failures. In short, while dependencies and interdependencies exist everywhere, they rarely appear to be strong enough to trigger a reported serious cascading CI outage. It is unclear whether this is because the $\mathrm{CI}$ operators manage the (inter)dependencies effectively or because the dependencies arent that powerful to begin with. In any 
Table 4: Cascade initiated events categorised by CI sector service (percentage of events contributed to an affected sector).

\begin{tabular}{|c|c|c|c|c|c|c|}
\hline \multirow[b]{2}{*}{ Affected Sector } & \multicolumn{2}{|c|}{ Energy Sector } & \multicolumn{4}{|c|}{ Telecom Sector (excl. Internet) } \\
\hline & 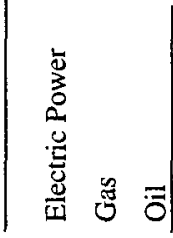 & 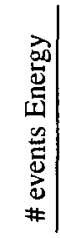 & 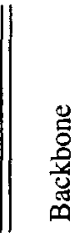 & 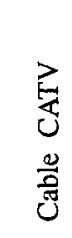 & 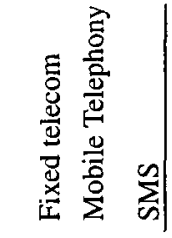 & 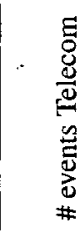 \\
\hline Educati & $133 \%$ & 11 & & : & & 0 \\
\hline Energy & $81 \% 1 \% 4 \%$ & 65 & & & $2 \%$ & 2 \\
\hline Financial Services & $19 \%$ & 5 & $8 \%$ & & $50 \%$ & 15 \\
\hline Fond & $75 \%$ & 3 & & & & 0 \\
\hline Government & $40 \% 3 \%$ & 17 & $3 \%$ & $3 \%$ & $23 \% 8 \%$ & 14 \\
\hline Health & $69 \%$ & 11 & & $6 \%$ & $6 \%$ & 2 \\
\hline Industry & $80 \%$ & 12 & & & & \\
\hline Internet & $27 \%$ & 13 & $20 \%$ & $12 \%$ & $23 \%$ & 27 \\
\hline Postal Services & & 0 & & & & 0 \\
\hline Telecom & $49 \% \quad 1 \%$ & 62 & $7 \%$ & $2 \%$ & $32 \% 3 \%|\%|$ & 57 \\
\hline Transport & $\mid 76 \% \quad 1 \% \quad 1 \%$ & 98 & & & $2 \% 2 \%$ & 5 \\
\hline Water & $78 \%$ & 14 & & & & 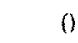 \\
\hline Total & $59 \% 1 \% 1 \%$ & $60 \%$ & $4 \%$ & $2 \%$ & $16 \% 2 \% 0 \%$ & $24 \%$ \\
\hline \# of events & $294 \quad 4 \quad 4$ & 302 & 22 & 11 & $78 \quad 10$ & 122 \\
\hline
\end{tabular}

Table 5: Categorisation of number of CI events (\# of events $\mathrm{CI}$ sector to sector).

\begin{tabular}{|c|c|c|c|c|}
\hline Initiating Sector & $\mid \begin{array}{l}\text { Avg. \# of resulting } \\
\text { events if cascading }\end{array}$ & $\begin{array}{r}\text { ample } \\
\text { size }\end{array}$ & $\begin{array}{l}\text { Avg. \# of resulting } \\
\text { events from all events }\end{array}$ & $\begin{array}{r}\text { ample } \\
\text { size }\end{array}$ \\
\hline Education & - & 0 & 0.00 & 4 \\
\hline Energy & 2.06 & 146 & 0.51 & 590 \\
\hline Financial Services & 3.00 & 1 & 0.05 & 60 \\
\hline Food & - & 1) & 0.00 & 8 \\
\hline Government & 1.00 & 2 & 0.03 & 67 \\
\hline Health & 1.00 & 1 & 0.03 & 39 \\
\hline Industry & 2.20 & 5 & 0.37 & 27 \\
\hline Internet & 1.20 & 15 & 0.11 & 160 \\
\hline Postal Services & 1.00 & 1 & 0.11 & 1 \\
\hline Telecom & 1.86 & 69 & 0.43 & 295 \\
\hline Transport & 1.26 & 19 & 0.06 & 422 \\
\hline Water & 1.67 & 9 & 0.20 & 76 \\
\hline Total & 1.88 & 268 & 0.29 & $\overline{1749}$ \\
\hline
\end{tabular}


case, it seems that $\mathrm{CI}$ are either more loosely coupled than the Domino Theory suggests, or that the $\mathrm{CI}$ dependencies occur at a more technical level not becoming visible to news reports.

Of course, there are a couple of qualifications that go with this conclusion. First of all, our findings do not rule out the possibility of multi-sector failure i.e., we still face the possibility of scenarios of low probability and high consequence. Second, even if the Domino Theory is misleading, that does not negate the fact that damages resulting from cascades initiated by the energy and telecommunication sectors can be substantial. The third implication of our analysis is that it does not support the idea that $\mathrm{Cl}$ dependencies are the unmanaged challenge. While there is an intuitive appeal to this idea, it may in fact be a myth. If we assume a vast web of dependencies that can trigger cascades, then it seems inevitable that we end up with a shortfall in the governance of this risk. But the evidence suggests that even if we assume this shortfall to exist, it does not translate into frequent deep cascades. Dependencies seem to be anything but unmanaged. Nevertheless, governance is needed. For instance, the high reliability of electricity and other $\mathrm{CI}$ services is anything but guaranteed in Europe. Moreover, the CI sectors that depend on the energy and telecom sectors can improve their strategies to manage those dependencies. In sum, the sobering conclusion emerges that CI cascading dependencies are focused to a limited number of CI sectors, occur more frequently than expected, and do not often cascade deeply.

Acknowledgements The research described above was partly funded by the EU Commission as part of the 6th framework programme project IRRIIS under contract number FP6-2005-IST-4 027568 and partly under the Dutch Next Generation Infrastructure (NGI) research programme.

\section{References}

1. European Commission, Proposal for a Directive of the Council on the identification and designation of European Critical Infrastructure and the assessment to improve their protection, COM (2006) 787 final, Communication from the Commission to the Council and the European Parliament, Brussels, 12 December 2006.

2. Auerswald, P.E., Complexity and Interdependence: The Unmanaged Challenge in: Seeds of Disaster, Roots and Response: How Private Action can Reduce Public Vulnerability, Edited by P.E. Auerswald, L.M. Branscomb, T.M. La Porte, and E.O. Michel-Kerjan, Cambridge, 2006, p. 157.

3. Pederson, P., Dudenhoeffer, D., Hartley, S. and Permann, M., Critical Infrastructure Interdependency Modeling: A Survey of U.S. and International Research, 2006.

4. Rinaldi, S.M., Peerenboom, J., Kelly, T., Complexities in identifying, Understanding, and Analyzing Critical Infrastructure Dependencies, Special issue IEEE Control Systems Magazine on Complex Interactive Networks, December 2001.

5. Simonoff, J., Restrepo, C., Zimmerman, R., Naphtali, Z., Analysis of Electrical and Oil and Gas Pipeline Failures, in: Critical Infrastructure Protection edited by E. Goetz and S. Shenoi, IFIP WG 11.10 series in Critical Infrastructure Protection, 2008.

6. Svendsen, N.K., and Wolthuysen, S.D., Connectivity models of interdependency in mixedtype critical infrastructure networks, Information Security Technical Report Vol 12, No 1, pp 44-55, Elsevier, ISSN 1363-4127, 2006.

7. Zimmerman, R., Restrepo, C., The next step: Quantifying infrastructure interdependencies to improve security, International Journal of Critical Infrastructures, vol 2(2-3), pp 215-230, 2006.

8. Von Kirchbach, H-P. et al, Bericht der Unabhngigen Kommission der Schsischen Staatsregierung Flutkatastrophe 2002, 2003. 
9. UCTE, Final report System Disturbance on 4 November 2006, UCTE, 2006. On-line: http: //www.ucte.org/入_ibrary/otherreports/Final-Report-20070130. pdf

10. ENSAD database, source: http://gabe.web.psi.ch/research/ra (last visited: July 29,2008 ) 